Revista de Economia Política, vol. 25, no 4 (100), pp. 454-475 outubro-dezembro/2005

\title{
Renegociação da D ívida Pública Interna em Condições de Sobreendividamento
}

\author{
RODRIGO OCTÁVIO MARQUES DE ALMEIDA*
}

Renegotiation of the public debt in conditions of excessive debt. This paper studies the debt overhang models and maturity management models, and analyses both theoretically and historically the debt renegotiations which the final outcome is a lower public debt burden. From the theoretical view the renegotiation plans can be Pareto improving, both creditors and debtors can be better-off, and the value of the new debt will price the new reputation and debtors' willingness to pay. From the historical point of view, funded debts were the instrument that debtors used to improve reputation.

Key-words: monetary policy; public debt management; debt overhang.

JEL Classification: H63;E43;E63.

\section{INTRODUÇÃO}

O objetivo deste artigo é explorar a viabilidade da renegociação de dívidas internas. Sob certas condições, esta renegociação causaria danos mínimos ao mercado de capitais. O s estudos anteriores com relação ao fim do endividamento elevado, em geral, concentram-se no aspecto da compulsoriedade do alongamento ou do cancelamento ${ }^{1}$. O s estudos de caso aqui descritos têm a virtude de serem citados como episódios positivos de renegociação e alongamento. ${ }^{2} \mathrm{~A}$ idéia subja-

* Doutor em Economia pelo Instituto de Pesquisas Econômicas da Universidade de São Paulo - IPEUSP. E-mail: roctavio@uol.com.br. 0 autor agradece os comentários de Álvaro Zini Jr (in memorian), Basília A guirre, Joaquim Elói Cirne de Toledo, Samuel Pessoa, Zeina Latiff, John Shulz, André Lunardelli , Claúdia Viegas, Ernesto Lozardo. Submetido: dezembro 2002; aceito: fevereiro 2005.

${ }^{1}$ Ver M akinen e Woodward (1990), Eichengreen (1990) e Alesina (1988) como exemplos.

${ }^{2}$ Dornbush (1991). 
cente é de que a renegociação coloca o tesouro novamente em sua restrição orçamentária, auxiliando na credibilidade da política de estabilização que em geral acompanha tais episódios. No entanto, para que qualquer estratégia de renegociação obtenha êxito, é necessário que se criem mecanismos institucionais que garantam que os recursos serão destinados ao lastro do novo endividamento. A lém desta introdução, o artigo está dividido em outras 5 partes.

A segunda seção apresenta os principais modelos de dívida soberana como objetivo de mostrar as condições em que as estratégias de renegociação de dívida via mercado podem ser bem-sucedidas, bem como o fato de que estas estratégias apresentam resultados semelhantes às mais tradicionais, como a simples recompra, seja financiada com recursos próprios, seja com recursos de terceiros.

D essa forma, tanto teórica quanto historicamente, as estratégias de renegociação através da escolha de um conjunto de opções ao estilo do Plano Brady³, não são diferentes dos planos de renegociação baseados em fundos de amortização, típicos dos séculos XVIII eXIX.

A seção 3 estende o conceito de sobreendividamento para o caso em que a dívida é de curto prazo. A seção 4 resenha algumas soluções para o problema do sobreendividamento.

A seção 5 examina dois episódios históricos de renegociação. Estes foram escolhidos, pois em geral considera-se que não houve compulsoriedade na conversão. $\mathrm{O}$ primeiro caso analisa o fundo de amortização proposto por A lexander $\mathrm{Ha}$ milton logo após a Guerra de Independência A mericana, enquanto o segundo caso é dedicado à experiência do franco poincaré implementado em 1926 na França.

0 fundo de amortização era uma instituição que tinha o mesmo papel do Tesouro, no que se refere à administração dos passivos do governo, utilizava as dotações do Tesouro e na prática realizava a operação de troca dos títulos de curto prazo por títulos de longo prazo a taxas de juros menores. É um instrumento primitivo de administração de dívida que, apesar de muitas vezes ineficaz, resistiu quase dois séculos, retornando na década de 90 no formato do Plano Brady4. A última seção será reservada às conclusões.

\section{MODELOSTEÓRICOS DE SOBREEN DIVIDAM ENTO SOBERANO}

Esta seção procura mostrar as condições teóricas para o sucesso das diferentes estratégias de redução de dívida, bem como sua equivalência.

Eichengreen (1990), em um artigo que discute os aspectos teóricos e históricos do imposto sobre a riqueza (capital levy), sugere que a crescente literatura

\footnotetext{
${ }^{3}$ O Plano Brady foi um plano de reestruturação da dívida dos países em desenvolvimento no início da década de 90. O Plano baseava-se na utilização de garantias e de um cardápio de opções de títulos que atendia à necessidade dos diferentes credores.

${ }^{4}$ Garber (1991) compara do ponto de vista histórico o Plano Brady com a estratégia de menu adotada por Alexander Hamilton em 1790.
} 
sobre dívida soberana ${ }^{5}$ endereçava a questões importantes na discussão. U ma delas era de que a imposição de imposto sobre a riqueza impunha uma transferência de renda daqueles que detinham a dívida para aqueles que pagavam impostos. N o entanto, não se podia afirmar que o endividamento subseqüente seria exitoso, uma vez que, se por um lado, ao sair do sobreendividamento o capital levy reduzia os custos do serviço da dívida, por outro lado, a crença de que este imposto poderia se repetir desencorajava a poupança, obrigando ao pagamento de um prêmio de risco maior. Utilizando um modelo de dívida soberana proposto por G rossman e Van H uyck (1988), Eichengreen trata a dívida doméstica como uma obrigação contingente de Estado. Sob certas circunstâncias, os credores reconheceriam a impossibilidade do pagamento em caso de um cenário negativo, e o governo poderia não pagar, ou impor um imposto sobre a riqueza, sem que existissem problemas para o novo endividamento. ${ }^{6}$

U ma abordagem alternativa pode ser implementada também utilizando a literatura de dívida soberana.

$\mathrm{N}$ a segunda metade dos anos oitenta, diante do prosseguimento do impasse no tocante à crise da dívida externa, al guns economistas preocupados com as conseqüências perversas disso sobre os investimentos nos países em desenvolvimento, procuraram desenvolver modelos analíticos para demonstrar a superioridade de alternativas que permitissem a redução e reestruturação do estoque de dívida pendente. $\mathrm{N}$ este sentido, surgiram dois grupos de modelos construídos com base no impacto sobre os investimentos advindos da crise da dívida ${ }^{7}$,os que seguem 0 artigo original de Sachs (1989a) (com extensões feitas por Corden (1989), Froot (1989), H elpman (1989) e K rugman (1988)), onde um planejador central maximiza uma função de bem-estar da população, e aqueles, como Borenztein (1990), que analisam uma função de investimento colocada no contexto de um problema de maximização dos lucros da firma. Sachs (1989a) centra-se principalmente no efeito desincentivo causado por uma situação de sobreendividamento. Isto o levou a dizer que:

"Since debt forgiveness overcomes economic inefficiencies that hamper the grow th the debtor, it is not surprising that debt forgiveness can be designed in such a way as to improve the position of both the creditors and debtors". (Sachs (1989a: 91)

K rugman (1988), por sua vez, define uma situação de debt overhang como a presença de um estoque de dívida suficientemente grande para que os credores passem a não ter mais confiança de que ele seja plenamente pago. 0 conceito de debt

\footnotetext{
${ }^{5}$ Para uma resenha desta literatura veja Eaton (1993) e Eaton e Fernandez (1995).

${ }^{6}$ Dessa forma, o modelo consegue lidar com a questão da inconsistência temporal, como discutido por Kyndland e Prescott (1977).

${ }^{7}$ Utilizando a definição de Claessens \& Diwan (1990), o investimento pode ser visto em sentido mais amplo, significando mudanças que imponham custos no presente, mas que rendam benefícios de longo prazo, tais quais políticas que ampliem a eficiência alocativa e a mobilização de recursos, bem como cortes em programas de gastos públicos de baixa eficiência.
} 
overhang, que se firmou nesta literatura, pode ser estendido para o caso em que a dívida pública apresenta prazos de vencimentos extremamente curtos, como se verá adiante, sugerindo que existe, além de um montante ótimo, um prazo de maturidade ótima, dada uma certa quantidade de dívida ea situação de finanças públicas.

0 objetivo do modelo-padrão de sobreendividamento é demonstrar que grandes montantes de endividamento geram ineficiências alocativas, deprimindo 0 investimento. ${ }^{8}$ Este ef eito ocorre porque 0 autor coloca como uma das suas hipóteses o funcionamento de uma regra de pagamento, na qual, se existe sobreendividamento, haverá um pagamento como proporção do produto, caso contrário 0 pagamento será lump-sum ${ }^{9} .^{10}$ Esta teoria implica que, para eliminar os efeitos distorcivos sobre o produto, é necessária a formulação de contratos que desvinculem os pagamentos dos retornos futuros.

As hipóteses do modelo são as que se seguem.

O comportamento do país devedor é determinado por um planejador central que maximiza uma função objetivo de dois períodos.

$$
\begin{aligned}
& W=U(C 1)+b U(C 2) \\
& \text { onde } \\
& W=\text { função de bem-estar do devedor } \\
& U(C 1)=\text { consumo agregado do período } 1 \\
& U(C 2)=\text { consumo agregado do período } 2 \\
& b=\text { fator de desconto intertemporal do devedor }
\end{aligned}
$$

Existe um montante de dívida total T, que é pulverizado entre vários credores. Suponha um acordo entre os credores e o devedor que implica a seguinte regra de pagamento ${ }^{11}$ :

$$
\begin{aligned}
& \mathrm{S}=\mathrm{T} \text { se } \mathrm{T}<\mathrm{zQ} 2 \\
& =\mathrm{ZQ} 2 \text { se } \mathrm{T}>\mathrm{zQ} 2
\end{aligned}
$$

onde

$\begin{array}{ll}\mathrm{Q} 2= & \text { produto do segundo período } \\ \mathrm{T}= & \text { montante contratual da dívida } \\ \mathrm{S}= & \text { montante a ser pago pelo acordo } \\ \mathrm{Z}= & \text { "alíquota de imposto" causada pelo debt overhang }\end{array}$

\footnotetext{
8 "In general, when future contractual obligations falling due are large, they can act as a tax on investment, since a share of the return will go to creditors" Claasens \& Diwan (1990).

${ }^{9}$ M yers (1977) foi o primeiro a mostrar a existência de níveis de investimentos subótimos na presença de sobreendividamento para o caso de empresas.

${ }^{10}$ Segundo Schwartz \& Z urita (1992): “Under investment is more likely to be a problem in the case of sovereign debt considered here than in the case of corporate debt originally studied by $\mathrm{M}$ yers (1977), as in the case of countries it is more difficult to enforce restrictive covenants on the debtors. For example, dividend restrictions at the firm level are easier to enforce than consumption constraints at the country level." (p.983)
}

${ }^{11}$ Sachs (1989a) não explica como se dá o processo de barganha desta negociação. 
Se a dívida é menor do que zQ 2, então, a dívida é plenamente paga, se não ZQ 2 é pago.

A ssuma ainda que existam apenas dois períodos, o devedor entra no primeiro período com montante de dívida a pagar no segundo período igual a $D$ ( não existe dívida a pagar no primeiro período ).

Os credores podem decidir, no primeiro período, perdoar algumas obrigações do segundo período. Se eles fazem isso, eles escolhem um montante $R$ que seja menor que D. Caso contrário, o montante a pagar será $D$. A tecnologia de produção é uma função linear do investimento no período 1 e as oportunidades de investimentos são delimitadas por I.

$$
\mathrm{Q} 2=\mathrm{Q} 1+(1+\mathrm{g})|1| 1<1
$$

onde

$\mathrm{g}=$ taxa de retorno do investimento

O objetivo dos credores é maximizar a última parcela de pagamento, S. O problema do credor será:

$$
\text { M ax S sujeito a } R<D
$$

$O$ devedor escolhe o nível de pagamento, $R$, que maximiza o serviço da dívida $S$, sujeito a restrição de que $R$ seja menor que $D$.

Assumindo que todo o investimento provém de poupança interna, uma vez que existe restrição ao crédito externo e se a alocação de poupança e o consumo são feitos por um planejador social, então o problema do planejador será:

$$
\begin{aligned}
& \mathrm{M} \text { ax } \mathrm{U}(\mathrm{C} 1)+\mathrm{bU}(\mathrm{C} 2) \\
& \text { tal que } \mathrm{C} 1=\mathrm{Q} 1-\mathrm{I} 1 \\
& \mathrm{C} 2=\mathrm{Q} 2(\mathrm{I})-\mathrm{S}
\end{aligned}
$$

Note que desde que $\mathrm{S}=\mathrm{ZQ} 2$ nós podemos escrever

$\mathrm{C} 2=(1-\mathrm{z}) \mathrm{Q} 2$

Definindo a condição de primeira ordem:

$$
(1+g)=a \cdot U^{\prime}(C 1) / U^{\prime}(C 2)
$$

onde $a=1 / b(1-z)$

Suponha que a dívida seja reduzida para um nível S* onde ela será plenamente paga. 0 devedor terá o mesmo problema de maximização, mas agora com S* e não com S. Como os pagamentos não são mais fixos em ZQ 2, a condição de primeira ordem será:

$$
(1+g)=k \cdot U^{\prime}(C 1) / U^{\prime}(C 2)
$$

onde $\mathrm{k}=1 / \mathrm{b}$

Dessa forma a taxa de retorno do investimento será igual à taxa marginal de substituição do consumo do primeiro pelo do segundo período.

Comparando ambas as equações, é fácil mostrar que o investimento será maior quando a taxa de retorno deste for maior, uma vez que as equações dife- 
rem apenas pela presença de $z$. Assim, o sobreendividamento age como um imposto que distorce a taxa de retorno do investimento e, logo, o próprio investimento, desde que um aumento no produto é taxado pela taxa marginal $z$, quando vista na perspectiva dos devedores.

Conclui-se que, na ausência de incerteza, a melhor política a ser seguida será um perdão parcial do estoque da dívida.

0 conceito descrito acima é semelhante ao conceito de curva de Laffer para o endividamento, exposto inicialmente por Krugman (1989), segundo o qual o valor presente dos pagamentos esperados poderia começar a cair a partir de certo nível elevado de endividamento.

Essa curva de Laffer também pode ser usada como argumento para o perdão parcial da dívida.

A lógica é simples: se o país está do lado decrescente da curva, uma redução do estoque da dívida conduz a um aumento do valor de mercado da dívida restante e assim beneficia os credores. Se o país está do lado crescente da curva, um perdão da dívida não eleva o valor de mercado dos títulos e os credores, como um todo, perderão. Este argumento pode não apenas ser utilizado para o perdão parcial da dívida como também para os chamados esquemas de redução de dívida via mercado, tais como securitização ou conversão de dívida em investimento. Estas estratégias serão analisadas com mais detalhe à frente. K rugman (1989) demonstra que as estratégias de reestruturação de dívida só trarão benefícios a ambas as partes se o grau de endividamento do país o tenha conduzido para o lado direito do ponto máximo da curva.

A figura 1 ilustra a relação acima descrita e postulada em Sachs (1989a e b) e Krugman (1989), entre o valor de face da dívida e o valor de mercado dos pagamentos futuros esperados.

Figura 1

Curva de Laffer para o Endividamento

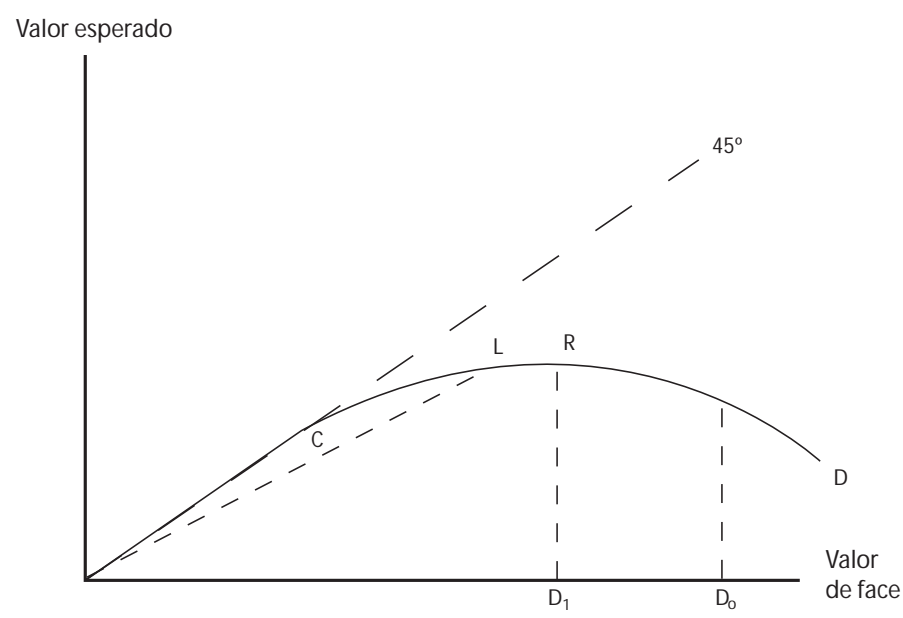


No eixo horizontal, representa-se $o$ valor nominal de face das obrigações e no eixo vertical, o valor presente dos pagamentos esperados pelo mercado. A baixos níveis de endividamento, os credores esperam que a dívida seja totalmente paga. 0 preço no mercado será 1 , e o valor da dívida estará sobre a reta de $45^{\circ}$. Com altos níveis de endividamento, no entanto, a possibilidade de pagamento parcial se eleva, com o devedor tendo poucos incentivos a investir, em virtude das ineficiências que o serviço da dívida impõe, e o valor de mercado cai abaixo da linha de $45^{\circ}$. No ponto D2, o endividamento se torna tão grande e o estoque dívida (valor de face) atua como desincentivo ao ajuste do devedor, levando à queda do preço de mercado dos títulos ${ }^{12}$.

Cline (1995) sugere uma visão alternativa ao efeito desincentivo; para ele existe mais espaço para uma explicação do que ele chama de risk compensated debt forgiveness, na qual os credores recebem garantias em troca da redução de qualquer imposto marginal sobre novos investimentos. Cline aponta, que existe um jogo de soma positiva se uma terceira parte garante e provê os colaterais para a reestruturação da dívida. $\mathrm{N}$ o caso da dívida externa, títulos do tesouro americano cumpririam este papel no contexto do Plano Brady. No caso mais específico da dívida interna, esta estratégia pode ser vista como a criação de uma caixa de amortização.

\section{A REDUÇÃO DE PRAZOSE O SOBREEN DIVIDAMENTO}

Pouca atenção analítica tem sido dada ao perfil temporal do endividamento do Governo e os problemas que este pode trazer. De fato, o crescimento da dívida, a prazos curtos, na ausência de uma estrutura de indexação que goze de credibilidade e permita 0 alongamento de vencimentos, pode se tornar um debt overhang, obrigando a uma renegociação de contratos.

A definição de sobreendividamento das seções anteriores colocou, no contexto da dívida soberana, um fenômeno antes analisado pela teoria de finanças corporativas. M yers (1977) produziu o artigo seminal sobre o tema mostrando que o sobreendividamento produzia um nível de investimento subótimo para a firma (underinvestment problem). M yers (1977) também procura demonstrar a relevância da estrutura de maturidade do endividamento como forma de reduzir o underinvestment problem, bem como discute qual o mix de maturidade ótimo sobre diferentes hipóteses com relação aos estados da natureza, variância da estrutura a termo de taxa de juros na melhora na percepção de risco de crédito.

A comparação entre o modus operandi de endividamento da firma e dos países emergentes foi desenvolvida em diferentes modelos. Diwan \& Acharya (1993),

\footnotetext{
${ }^{12}$ U ma extensão para o caso da dívida interna brasileira, que é composta em sua maior parte por títulos atrelados a taxa de juros de curto prazo, significaria que, uma vez estando do lado "errado" da curva, uma forte redução da taxa de juros recomporia a solvência do devedor e o traria para o lado esquerdo da curva em linha com Bresser-Pereira e $N$ akano (2002).
} 
por exemplo, demonstram analítica e empiricamente que as recompras servem como indicadores de credibilidade para países que desejam responder ao perdão parcial da dívida aumentando investimentos e os pagamentos futuros da dívida.

"...observe that the country's debt buyback decision is analogous to that of a firm, although the country signals its willingness to invest while a firm is postulated to signal its future earnings prospects." (p.191)

Alguma intuição sobre o alongamento pode ser tirada da teoria de finanças corporativas e da forma como as firmas escolhem o mix de maturidade bem como o grau de amortização de suas dívidas. A hipótese para que se possa utilizar este tipo de abordagem é de que o título público é, devido à má reputação do seu emissor, um título de risco e que sua demanda depende em última instância da avaliação deste risco pelo mercado, assim como da sinalização das políticas por parte do emissor.

No caso da dívida externa em que o default ocorre de forma explícita, a existência do fundo de amortização demonstra a qualidade do devedor. No entanto, no caso de dívidas denominadas em moeda nacional, para que possa haver endividamento a prazos mais dilatados, é necessário um comprometimento adicional com as políticas monetária e cambial, de forma que estas não sejam consideradas oportunistas. Em geral, os model os que trabalham com a reputação dos devedores colocam como hipótese a capacidade dos agentes de reconhecer quando, por exemplo, a inflação está sendo utilizada com o objetivo de reduzir o valor real da dívida ${ }^{13}$.

Diversos modelos têm procurado, de forma explícita ou implícita, considerar a possibilidade de oportunismo na política econômica.

N o contexto da minimização de custos sociais, M isale \& Blanchard (1991), tentam calcular a maturidade máxima a ser escolhida e praticada pelo governo, levando em consideração sua reputação como devedor. $\mathrm{N}$ a presença de títulos de maturidade longa ou sem indexação plena, o governo tem liberdade de gerar políticas oportunistas tais como a utilização de inflação não esperada, de forma a amortizar parte de seu endividamento. Desta forma, ao elevar seu nível de endividamento, o governo, para se manter consistente com sua reputação, tenderá a encurtar seus prazos, ou a aumentar o grau de indexação de sua dívida.

Calvo \& Guidotti (1990) demonstram a necessidade de um precommitment na gestão da dívida pública. Pelo modelo, havendo a existência deste, uma dívida de longo prazo seria ótima. Caso não exista, a dívida curta dominaria, para evitar que o governo use a inflação como forma de amortização. 0 precommitment é por definição a capacidade que o governo tem em um instante zero de comprometer o curso das políticas futuras de seus sucessores nos períodos seguintes. Como a existência de títulos nominais pode conduzir à utilização da inflação como forma de repúdio, o precommitment, neste modelo, vem na forma da indexação dos títulos no nível geral de preços.

${ }^{13}$ Veja, por exemplo, Grossman \& Van H uyck (1993). 
0 encurtamento de prazos implica no maior risco de uma corrida contra os títulos. Em geral, os modelos de corrida contra a dívida baseiam-se nos pressupostos de Diamond \& Dybvig (1983), em que os credores recusam-se a financiar um devedor (no caso um banco) que é solvente, porém está ilíquido, porque acreditam que todos farão 0 mesmo ${ }^{14}$.

\section{DIFERENTES SO LUÇÕES PARA \\ O PROBLEM A DO SOBREEN DIVIDAMENTO}

A literatura sobre o gerenciamento das dívidas externa e interna mostra uma gama de estratégias para a redução do estoque e alongamento de prazos, dependendo do tipo de dívida. A maior parte tenta capturar para o devedor a diferença entre o valor contratual de um débito e o preço do mercado secundário. Esta seção analisará algumas delas.

\subsection{Recompra e Perdão}

A recompra de títulos no mercado secundário é uma das estratégias mais debatidas em termos práticos e teóricos. Consiste em simplesmente, utilizando recursos próprios ou de algum organismo internacional (FM I, Banco M undial), beneficiar-se do desconto do mercado secundário e recomprar seus próprios títulos. ${ }^{15}$

A questão fundamental é de onde partem os recursos para a recompra dos papéis e até que ponto credores e devedores ganham. Um ponto até então consensual na maioria das análises, até meados dos anos oitenta, era de que se o devedor estivesse do lado direito da Curva de Laffer de Endividamento, a recompra possibilitaria um ganho para o devedor sem implicar em perdas para o credor.

N esta linha, o artigo de Froot (1989) resume bem as proposições discutidas. Existem 4 fontes alternativas de recursos para um programa de recompras: a) os credores fornecem os recursos através do perdão parcial, b) doações de outros governos ${ }^{16}, c$ ) o fluxo de recebimentos futuros do devedor (por exemplo, exportações), d) reservas internacionais.

Pautando-se em hipóteses gerais, que permeiam a maioria dos modelos de sobreendividamento de países, Froot (1989) demonstra as 4 proposições a seguir: (1) 0 perdão parcial da dívida só beneficia a ambas as partes caso o problema de investimento subótimo seja significativo, ou seja, que o devedor se encontre

\footnotetext{
${ }^{14}$ N essa linha tem-se Giavazzi \& Pagano (1990) e Alesina, Prati \& Tabellini (1990) seguem essa abordagem.

${ }^{15}$ Eaton (1993) questiona que, se o valor de mercado dos títulos sobe quando o estoque de dívida cai, os investidores deveriam "perdoar" a dívida até a maximização do seu preço. Isto não ocorre, pois toda a estratégia de redução de dívida negociada envolve dois tipos de problemas: coordenação entre os credores e o "problema do carona".

${ }^{16}$ Este tipo de financiamento é particularmente relevante para países africanos.
} 
no lado direito da curva de Laffer de Endividamento. Caso contrário, apenas o devedor se beneficiará. (2) R ecompras feitas com recursos provenientes de donativos beneficiam os devedores no mesmo nível que o perdão, mas aumentam os ganhos dos credores, no montante doado. (3) A utilização de bônus de saída, onde a dívida velha é trocada por uma nova capturando o desconto do mercado secundário, tendo seu preço baseado nos recursos futuros a serem gerados pelo país, tem o mesmo efeito do perdão parcial. (4) O s efeitos positivos de uma recompra, baseados em recursos próprios em termos de bem-estar e incentivo para o país devedor, são menores que os efeitos de um perdão parcial simples e daquele financiado com doações.

\subsection{Securitização (Troca de Dívida/Fundo de Amortização)}

K rugman (1989) mostrou que o processo de securitização de dívidas só pode ser implementado com sucesso, caso esta alternativa seja percebida como meIhor do que a anterior.

A única maneira de um esquema de securitização de dívidas ter êxito é se a nova dívida for reconhecidamente mais segura. Caso contrário, esta terá a mesma probabilidade de não-pagamento da dívida antiga e logo será vendida ao mesmo desconto, implicando que não haverá redução líquida do estoque de dívida.

Existem 3 fatores que podem fazer o instrumento mais seguro. Primeiro, os credores podem coletivamente concordar que o título novo é melhor que as outras dívidas do governo, ou seja, que a possibilidade de repúdio é menor, fato que dificilmente ocorre. 0 segundo, uma entidade extragoverno pode garanti-los, emitindo a dívida nova com garantias tangíveis do principal e/ou dos juros. Esta entidade pode ser um órgão que administre as dívidas antiga e nova do Governo, colocando seus fundos não disponíveis a quaisquer outros gastos que não sejam a amortização de parcela da dívida nova. Ela tem a virtude de estabelecer uma regra de endividamento para o Governo. Terceiro, o novo título deve ter direitos especiais de conversão, como, por exemplo, o pagamento de impostos devidos com os novos títulos.

No contexto da dívida interna, a securitização é o mesmo processo de lastreamento em que se amortiza a dívida velha com um mix de pré-pagamento e conversão (debt-debt swap).

A securitização pode em última instância beneficiar credores e devedores meIhorando os termos em que a dívida foi inicialmente contratada. A securitização pode também ser vista como uma forma de precommitment, permitindo 0 alongamento da dívida. Esta seria uma alternativa à indexação plena e de curto prazo como forma de precommitment, sugerida nos artigos resenhados na seção anterior. 


\subsection{Cancelamento Parcial Compulsório ou Capital Levy (Imposto sobre o C apital)}

O recurso do capital levy pode ocorrer toda vez que o Governo emitir uma dívida na moeda do país. 0 capital levy pode tomar várias formas, entre elas inflação não esperada (quando a dívida não tem indexação plena), através de um único salto ou (des)valorização cambial ${ }^{17}$. Este recurso foi proposto por Keynes (1923) e seu sucesso, como também afirma Spaventa( 1987), depende de condições especiais, difíceis de ser encontradas nas novas sociedades democráticas.

Uma das maneiras apontadas por Blanchard, Dornbush \& Buiter (1986) e por M isale \& Blanchard (1991) para reduzir o estímulo a esses cancelamentos parciais compulsórios, seria o encurtamento de prazos das dívidas nominais e possivelmente até a indexação plena de títulos, pagando-se um prêmio real. ${ }^{18}$

Eichengreen (1990) discute o capital levy utilizando um modelo de dívida externa soberana onde esta é tratada como uma obrigação dependente do estado da natureza do devedor. ${ }^{19}$ Isto implica, no caso do modelo, que os detentores dos títulos reconheceriam quando o Governo estaria em dificuldades, o que obrigaria a um default. A presença de uma cláusula implícita no contrato de dívida ${ }^{20}$ possibilitaria que a inadimplência não causasse nenhum trauma ao mercado. $\mathrm{N} o$ entanto, ele mesmo reconhece, pelas experiências históricas, que a aplicabilidade desta estratégia é dificultada em sociedades democráticas.

\section{ESTUDOS DE CASO}

\subsection{Estados U nidos $(1790)^{21}$}

O programa de amortização da dívida conduzido por A lexander $\mathrm{H}$ amilton, primeiro secretário do Tesouro americano, após a Guerra de Independência, foi uma das primeiras experiências em que a estratégia de "menu", tanto para a dívida externa quanto para a interna, foi conduzida com relativo sucesso, sendo considerada um exemplo da disposição de evitar o repúdio da dívida ${ }^{22}$. 0 estabe-

\footnotetext{
${ }^{17}$ A valorização cambial é considerada um tipo de "levy" quando aplicada sobre títulos referenciados em moeda estrangeira; a desvalorização se aplica no caso da moeda nacional.

${ }^{18}$ Pode-se argumentar que esses autores, assim como outros do ambiente anglo-americano, acreditam que cláusulas de indexação plena não podem ser burladas pelos Estados, fato que a experiência latino-americana recente demonstra ser incorreta.

${ }^{19}$ Ver Grossman \& Van Huyck (1988).

${ }^{20} \mathrm{~N}$ o sentido de que os agentes reconheceriam o motivo de força maior para que a dívida não fosse paga.

${ }^{21}$ As referências desta seção são: Studenski \& Krooss (1952), Calomiris (1988), Sylla, Legler \& Wallis (1987), Garber (1991) e Swanson \& Trout (1990).

${ }^{22}$ Barro (1987).
} 
lecimento de um fundo de amortização ${ }^{23}$ tinha como principal pressuposto, para o lançamento de novos títulos, que as taxas de retorno seriam menores nos anos seguintes de forma a aliviar os encargos do Tesouro. ${ }^{24}$

0 sistema monetário americano era razoavel mente primitivo antes da Guerra de Independência, com as colônias gozando de grande independência na emissão de moedas e títulos. A Igumas colônias emitiam commodity money baseado principalmente no tabaco. Também eram emitidas as bills of credit, que tinham curso legal e as quais as colônias aceitavam como pagamento de impostos ${ }^{25}$.

Durante a Guerra de Independência, o Governo através da Confederação dependia apenas de duas fontes de receitas: quotas impostas aos estados-membros e vendas de terras. A impossibilidade de gerar novas receitas refletia-se no acúmulo de dívida e na incapacidade de arcar com o serviço da dívida acumulada durante a Guerra, o que significava um montante de $31 \%$ da renda nacional ${ }^{26}$.

A partir de 1775, emitiu-se o Continental Bills of Credit, um título que funcionava como moeda e que pagava um cupom de juros.

0 valor dos continentals depreciou-se rapidamente desde então. Ao final de 1776, eram descontados a 50\% do seu valor de face e em 1780 a taxa de câmbio era de 40 continentals por um dólar de prata. A o final de 1781, a taxa de troca era de 1000 continentals por dólar de prata e o valor de face das emissões totalizava 360 milhões $^{27}$. Em 1780, uma reforma monetária relançou os continentals à taxa de $5 \%$ e com a promessa de pagamento em dólares de prata. No entanto, seu valor de face caiu para $1 / 8$.

Vários foram os fatores que impulsionaram a variação dos descontos dos continentals no período de 1775 a 1781, entre eles: vitórias ou derrotas durante a guerra, a aliança com a França e a política de indexação dos títulos e dos servidores públicos à taxa de expansão das notas e o crescimento de $170 \%$ do estoque nominal de moeda.

Em 1781, os continentals deixaram de ser meio de troca, sendo substituídos por produtos importados e por novas notas dos estados.

A falta de credibilidade da moeda era tal que o governador do estado de M assachusetts decidiu lastrear as dívidas do governo de seu estado com seus próprios bens e que passaram a ser chamadas $\mathrm{M}$ orris $\mathrm{N}$ otes ${ }^{28}$. A maior dificuldade

\footnotetext{
${ }^{23}$ O primeiro fundo de amortização formado como uma organização para administração de dívida surgiu na Inglaterra em 1716, este fundo, no entanto, "quebrou" uma vez que o parlamento passou a atribuir outras funções de gasto.

${ }^{24}$ (Swanson \& Trout 1990: 627).

${ }^{25}$ Durante o período que precedeu à Independência, as colônias expandiram muito suas emissões. N o entanto, este fato não significou inflação ou depreciação da moeda (apenas M assachusetts). Smith (1985) explica que isto ocorreu, inversamente ao que poderia prever a teoria quantitativa da moeda, porque as colônias não emitiam "fiat money", apenas dívidas que eram lastreadas em receitas futuras do governo.

${ }^{26}$ Estimativa de Barro(1987), citada em Garber (1991: 3).

${ }^{27}$ Garber (1991).

${ }^{28}$ Calomiris (1988: 60).
} 
do Congresso era, dado o seu pequeno poder de tributar, fazer com que os detentores de seus títulos acreditassem que estes seriam pagos ${ }^{29}$.

O s continentals foram inicialmente vendidos ao par, na crença de que haveria recursos suficientes para a amortização dos mesmos. Q uando esta crença se reduziu, el es passaram, então, por um processo de rápida depreciação. A emissão de moeda (bills of credit) era a única fonte de financiamento de guerra. 0 Congresso Continental tentou, no imediato pós-guerra, levantar empréstimos internamente, lançando títulos de 3 anos a 4\% de juros. A ausência de demanda, em virtude da baixa rentabilidade, obrigou à el evação da taxa para $6 \%$. A demanda surgiu principalmente porque o Congresso vinha recebendo contribuições dos estados e por causa de um empréstimo da França. Inicialmente os juros eram pagos em moeda, no entanto foram substituídos pelos certificados de juros não pagos (indents of interest), o que implicou, também, em rápida depreciação deste tipo de dívida.

Com o estabelecimento do Governo em 1789, este readquiriu o poder de tributar. Em 1790, Alexander H amilton, o primeiro Secretário do Tesouro dos Estados Unidos, através do seu Report on the Public Credit, propôs o estabelecimento de um fundo de amortização da dívida pública, a assunção das dívidas estaduais e a não-discriminação entre compradores de títulos nos mercados primário e secundário.

A proposta de $\mathrm{H}$ amilton de fundear a dívida interna sem discriminar os credores gerou grande controvérsia no Congress ${ }^{30}$. Alguns congressistas argumentavam que, em virtude dos deságios praticados no mercado secundário, deveria haver diferenciação entre os compradores originais e os compradores do mercado secundário, sendo no primeiro caso a conversão feita ao par, enquanto no segundo seria utilizado algum redutor. ${ }^{31}$

Coincidentemente a partir do First R eport, o valor de mercado dos títulos subiu com rapidez. $\mathrm{O}$ principal problema de $\mathrm{H}$ amilton era estimular a conversão dos consols de $6 \%$ para os de $4 \%$ de rendimento. 0 estímulo viria através da conversão dos novos títulos em terras e de tontinas ${ }^{32}$. N o entanto, caso existissem investidores que não quisessem entrar no plano de alongamento, a ameaça era de não-pagamento parcial. ${ }^{33}$

D esta forma, $\mathrm{H}$ amilton enviou para a aprovação do Congresso um menu de

\footnotetext{
${ }^{29}$ Pelos Artigos da Confederação, somente os estados tinham poder de tributar.

${ }^{30} \mathrm{Garber}(1991: 12)$.

${ }^{31}$ Swanson \& Trout (1990: 625) e Garber(1991: 13).

${ }^{32}$ As tontinas eram uma forma de anuidades vitalícias na qual os sobreviventes se beneficiam da morte de outros participantes. $\mathrm{N}$ os empréstimos de anuidades vitalícias do tipo consol o governo toma um empréstimo e devolve um fluxo de pagamentos durante a vida do investidor. As tontinas eram uma variante na qual os pagamentos não mais efetuados à medida que os subscritores iam morrendo eram redistribuídos entre os sobreviventes. A obrigação do governo apenas terminava quando o último membro do grupo morria. Era um sistema que misturava poupança com jogo. Ver Weir (1989).

${ }^{33}$ Swanson \& Trout (1990: 627).
} 
6 opções de conversão de dívida. Considerando-se o estoque de títulos antigos, incluindo-se os certificados de juros não pagos, o Tesouro emitiria uma das opções a seguir ${ }^{34}$ : (i) $66.67 \%$ da dívida pagando $6 \%$ de juros sobre o cupom e com amortização à escolha do Governo, mais $\$ 33.33$ em terras (avaliadas em 20 centavos por acre); (ii) $100 \%$ pagando $4 \%$ de juros de cupom, tendo a recompra limitada a $\$ 5$ por ano entre principal e juros e $\$ 15.8$ em terra (20 centavos por acre); (iii) $66.67 \%$ pagando $6 \%$ de juros e $\$ 26.88$ em deferred bonds, com recompra limitada ao montante de 4.67 e 1.88, respectivamente incluindo juros e principal; (iv) $100 \%$ a serem pagos em um prazo de 10 anos, em anuidades vitalícias pagando $4 \%$ ao ano; (v) $100 \%$ em anuidades vitalícias pagando 4\%, mas com pagamentos postergados até a morte do membro mais idoso da família; (vi) $100 \%$ em anuidades vitalícias pagando $5 \%$, adquiridas com $50 \%$ em dinheiro e $50 \%$ em títulos antigos tendo recompra limitada a $\$ 6$ por ano, entre juros e principal.

o Congresso aprovou apenas o terceiro item, incluindo ainda a emissão de títulos de 3\% de cupom para os juros atrasados, que seriam tratados como principal e convertidos na paridade 1 para 1.

As dívidas em atraso não pagariam juros até 1800 , quando seriam idênticas aos títulos de 6\%. O s continentals, por sua vez, teriam uma taxa de conversão de 100 para 1.0 s detentores de títulos teriam até um ano para entrar no programa, não havendo nenhuma conversão compulsória. No entanto, o orçamento de 1791 já não provisionava recursos, para o pagamento dos títulos fora do programa.

\subsection{FRANÇA $(1926)^{35}$}

A pós o término da Primeira Guerra, a França deparou-se com severas dificuldades financeiras em conseqüência da necessidade de gerar recursos consideráveis para a reconstrução física do país. A expectativa de que as reparações de guerra alemãs cobririam esses gastos foi a principal responsável pelo grande endividamento francês no imediato pós-guerra ${ }^{36}$.

A estrutura do orçamento do Estado comprova esta dependência. Este era composto de 3 partes: despesas ordinárias a serem cobertas pelas receitas correntes, despesas extraordinárias a serem cobertas por empréstimos de longo prazo e despesas de recuperação a serem cobertas por receitas das reparações.

Para seu financiamento interno de curto prazo, o governo dispunha basicamente de dois instrumentos: os Bônus da D efesa $\mathrm{N}$ acional (BDN ) e os adiantamentos do Banco Central ao Tesouro. O s BD N s tinham como características básicas: uma taxa dejuros fixa, denominações de 25 a 100.000 francos evencimentos de 1, 3, 6 e 12 meses.

Inicialmente, a despeito do seu rendimento fixo, os BDN s apresentaram boa

\footnotetext{
${ }^{34}$ Swanson \& Trout (1990) e Dunbar (1889).

${ }^{35}$ Para outras versões em português deste episódio, ver Zini (1992) e Almeida (1997).

${ }^{36}$ Dulles (1929).
} 
performance. $\mathrm{No}$ entanto, a crescente dificuldade em cobrar da A lemanha as reparações de guerra, e a tentativa frustrada de obtê-las a força com a invasão do vale do Ruhr, foi o ponto de partida para as dificuldades de colocação dos BDN junto ao público e dos crescentes adiantamentos do Banco da França ao Tesouro, o que na prática significava monetização da dívida.

Ao final de 1923, o governo enfrentaria dois graves problemas. Primeiro, a incapacidade do Tesouro em pagar 2 bilhões de francos ao Banco da França, como estipulado pela Convenção $\mathrm{M}$ arsall..$^{37} \mathrm{O}$ segundo foi uma corrida contra 0 franco. A mbos foram solucionados tanto com a aprovação de um aumento dos impostos indiretos quanto de um empréstimo externo.

Com a substituição do primeiro-ministro R aimond Poincaré em 1924, por uma coalizão de centro-esquerda ( $C$ artel des $G$ auches - $C d G$ ), tem-se um período de instabilidade política marcado principalmente pela incapacidade de se obter um consenso sobre um plano de ação econômica, bem como por constantes ameaças de capital levy. D essa forma, a França teve sete primeiros-ministros e nove ministros das finanças durante este período ${ }^{38}$. Foram analisadas pelos componentes do C dG três diferentes possibilidades para a solução do problema de financiamento: 1) uma consolidação forçada da dívida de curto prazo, 2) um imposto de capital (capital levy) e 3) a monetização da dívida de curto prazo com a el evação dos limites legais de emissão de notas pelo Banco da França. No entanto, a impossibilidade de se formar maioria no Congresso impediu a implementação de qualquer uma destas medidas.

As constantes ameaças de capital levy tornavam ainda mais difícil a rolagem da dívida de curto prazo e conduziam à fuga maciça de capitais.

A partir do segundo semestre de 1925, o Tesouro enfrentou grandes dificuldades na rolagem de mais de 40 bilhões de francos de títulos e no refinanciamento de 32 bilhões de títulos de longo prazo, sendo necessário o rompimento por três vezes dos limites legais dos adiantamentos do Banco da França ao Tesouro. 0 aumento da taxa de emissão de notas e da oferta monetária refletiu-se sobre 0 nível de preços. Para os períodos de maio-junho e junho-julho de 1926, a taxa anualizada de inflação projetada era de $136 \%$ e $346 \%$ respectivamente, sendo acompanhada de rápida depreciação do franco. ${ }^{39}$

Poincaré ${ }^{40}$ assumiu novamente o governo em julho de 1926 contando com a

\footnotetext{
${ }^{37} \mathrm{~A}$ Convenção $\mathrm{M}$ arsall estipulava que o Tesouro francês deveria pagar 2 bilhões de francos por ano de um total de 17 bilhões, ao Banco da França.

${ }^{38}$ Para uma descrição pormenorizada deste período que foi chamado de "valsa dos portfolios" veja Prati (1991).

${ }^{39}$ Para uma discussão sobre se a desvalorização cambial no período foi causada por fundamentos ou por especulação veja Eichengreen (1982), Sicsic (1992) e Eichengreen (1992).

${ }^{40}$ Poincaré era um político influente e conhecido. Primeiro foi deputado em 1887, pertenceu ao M inistério das Finanças em 1893; Vice-Presidente da Câmara de 1895 a 1897; M embro da Academia Francesa desde 1909, Primeiro-M inistro pela primeira vez em 1912; Presidente da República durante a Primeira Guerra, de 1913 a 1920. Peel (1937: 135).
} 
confiança da comunidade empresarial e da classe média. Implementou rapidamente um programa de ajustes inspirado em sua maior parte num relatório de especialistas (R apport des Experts) que havia sido publicado três semanas antes, ainda no governo de seu predecessor.

As principais medidas foram: 1) uma reforma tributária com o aumento dos impostos indiretos; 2) a implantação de uma Caixa de A mortização para os títulos de curto prazo, que dispunha de recursos próprios e era considerada o elemento psicológico do plano; 3) o retorno do franco ao padrão-ouro41. 4) corte nos gastos públicos com o objetivo de manter o orçamento estruturalmente equilibrado.

O Rapport des Experts propunha atacar o problema mais urgente: os Bônus da D efesa $\mathrm{N}$ acional.

“ O Comitê estima que é absolutamente indispensável seguir uma política de consolidação voluntária dos bônus da defesa. Para isto, ele recomenda oferecer aos portadores, logo que as circunstâncias pareçam favoráveis, um plano, primeiro de consolidação que responda às condições de mercado e ao legítimo desejo de segurança dos subscritores. Poderia igualmente ser vantajoso oferecer em favor dos portadores de BDN s, e mesmo de todos os outros bônus de curto prazo, facilidades de troca contra títulos existentes ou contra os títulos de novo tipo. Esperando que estas operações sejam realizáveis, é importante tomar uma série de medidas para que o desembolso dos bônus seja cercado de todas as garantias possíveis. Para isto, parece de primeira importância separar nitidamente a Tesouraria, dos bônus da defesa nacional, que devem ser considerados como um legado do passado." 42

O Rapport não mencionava a criação de nenhum imposto novo para dotar a Caixa de A mortização de recursos. $\mathrm{N}$ o entanto, sugeria tomar empréstimos a tão longo prazo quanto possível nos grandes mercados de capitais com o objetivo de proporcionar à França a reserva necessária para a estabilização de sua moeda.

Poincaré deu a necessária sustentação política ao projeto. Assim, "La Caisse autonome de gestation des bons de la defense nationale, d'exploitation industrielle des tabacs, et d'amortissement de la dette publique" foi criada por lei em 7 de agosto de 1926 e iniciou operações em 1 de outubro, sendo ratificada posteriormente através de emenda constitucional. Ela dispunha de 3 fontes distintas de receitas: 1) da administração do monopólio sobre a indústria de tabaco, 2) de um imposto de $7 \%$ sobre primeiras transferências de imóveis e fundos de comércio e 3) do produto dos direitos de sucessão, imposto sobre heranças.

O s BD N s eram recebidos como pagamento para as no.vas subscrições o Te-

\footnotetext{
${ }^{41}$ Durante o governo de Poincaré, o Banco da França era comandado por Emile M oreau com a colaboração de Charles R ist e de Pierre Q uesnay como diretor de estudos econômicos. $\mathrm{N}$ esse período existia uma grande controvérsia sobre a independência do Banco da França em relação ao dilema estabilização versus revalorização do franco. Para uma discussão sobre o jogo político por trás da estabilização, veja Schmid (1974).

${ }^{42}$ França (1926: 20), tradução e grifo do autor.
} 
souro, pelos termos da autorização prévia, descontava os BDN s na Caixa e, com estes encaixes, reduzia seus adiantamentos ao Banco da França ${ }^{43}$. Assim o efeito líquido era uma devolução dos bônus à Caixa para cancelamento, com uma correspondente redução nos depósitos da caixa no Banco da França. ${ }^{44 e 45}$

$\mathrm{N}$ a ocasião do estabelecimento da Caixa de A mortização, a composição da dívida de curto prazo era a seguinte: 1300 milhão de Bônus du Trésor e 47165 milhões de Bônus da D efesa $\mathrm{N}$ acional. $\mathrm{O}$ peso dos juros era relativamente elevado, representando 700 milhões por ano. Em relação ao vencimento da dívida, estava assim distribuída: 5 bilhões de bonus a um mês, 3 bilhões e 500 de bônus a três meses, 4300 a seis meses e mais 34 bilhões de bônus com prazo de um ano. O s pagamentos eram tais que a Caixa podia ser chamada a desembolsar 8 biIhões em um só mês ${ }^{46}$.

Como ainda existia muito pouca liquidez em caixa, a solução encontrada foi fazer um empréstimo emitindo 3 bilhões de obrigações de 500 francos da mesma categoria, tendo um juro fixo de $6 \%$ mais uma participação no benefício do monopólio do tabaco. Este empréstimo era reembolsável em 40 anos. As subscrições eram recebidas em Bônus do Tesouro ou em BDN s, e não em dinheiro líquido. Dessa forma a dívida flutuante caiu de 48 bilhões para 45 bilhões e pôde-se retomar a emissão dos bônus de curto prazo sem ultrapassar o teto fixado por lei. A partir de fim de outubro, voltou a demanda por títulos públicos. Eles levaram até o final de novembro mais de 3 bilhões em dinheiro novo.

Um outro problema era o alongamento de prazos propriamente dito. 0 objetivo era fazer os detentores de títulos realocarem seu portfólio, migrando de títulos de prazo curto para títulos de prazo longo, ou seja, de 2 anos. A técnica empregada foi reduzir os juros dos bônus de 3 e 6 meses em $1 \%$, em $0.5 \%$ aqueles de 1 ano, enquanto foram mantidos os de 2 anos.

Em 16 de dezembro de 1926 foi suprimida a emissão dos BD N s de 1 mês, em 22 de dezembro os de 3 meses, em 29 de janeiro de 1927 os de 6 meses e em 2 de junho de 1927 os de 1 ano. A partir desta data apenas títulos com 2 anos de maturidade podiam ser emitidos. Em 3 de junho de 1928 a dívida flutuante estava reduzida a 38 bilhões e era composta quase na totalidade de bônus de 2 anos. Em 21 meses a Caixa de A mortização reembolsou e consolidou 10 bilhões de bônus de curto prazo.

\section{CONCLUSÕES}

$\mathrm{N}$ as seções anteriores apresentamos teórica e historicamente as características do sobreendividamento e sua potencial solução através de diferentes estraté-

\footnotetext{
${ }^{43}$ Rogers (1929: 87).

${ }^{44} \mathrm{~A}$ pesar de serem entidades distintas, a Caixa de A mortização e a Caixa de D epósitos eram dirigidas pela mesma pessoa (J ean Tannery) e empregavam o mesmo pessoal. Ver Priouret (1966).

${ }^{45}$ Rogers(1929: 167).

${ }^{46}$ Priouret (1966).
} 
gias. Este sobreendividamento pode ser gerado tanto pela presença de um estoque grande quanto de prazos muito curtos. 0 pano de fundo para o sucesso das estratégias de mercado é a presença de novas instituições fiscais e monetárias que garantam o comprometimento do devedor bem como a transferência de riscos entre os diferentes credores.

As soluções sugeridas pela teoria que baseou os esquemas de renegociação via mercado e pelos casos históricos descritos implicam o aperfeiçoamento das instituições quando aplicadas a outros países. N os episódios descritos na seção 5 fica evidente a presença do componente ideológico e de coalizão política que impulsiona a mudança institucional. $\mathrm{No}$ caso de Alexander $\mathrm{H}$ amilton, pelo surgimento de uma nova nação, e no caso de Poincaré, a coalizão se deu com a presença de um primeiro-ministro conservador e um presidente do banco central indicado pela esquerda ${ }^{47}$.

Criar um fundo de amortização significa separar do Tesouro suas atribuições como gestor da dívida pública. Este fundo tem recursos e pessoal próprios para esse fim e em geral era elemento necessário para um plano de estabilização e de restabelecimento da confiança na dívida pública. Em conjunto com uma lei de orçamento equilibrado estabelece uma regra de endividamento, uma vez que limita a capacidade de endividamento do governo independente de qualquer choque, já que apenas a caixa de amortização pode emitir dívida ${ }^{48}$. N esse sentido, a delegação de poderes age como uma tecnologia de comprometimento em relação ao endividamento futuro, significando na verdade que é o pagador de impostos que deve pagar pelas oscilações no caixa do Tesouro e não o detentor de dívida.

A del egação doméstica da política fiscal era mais utilizada historicamente. $\mathrm{H}$ oje, no entanto, expedientes externos como a formação de federações fiscais e as condicionalidades do FM I também podem ser usadas. ${ }^{49}$

A separação do Tesouro era o mecanismo que estabelecia limites críveis à ação do Estado, reduzindo custos de transação e monitoramento, transferindo a administração da dívida para uma instituição independente com dotação própria garantidas por lei, que poderia ser acompanhada por um banco central independente. Em tese, havia toda uma legislação paralela dando as características e a forma de atuação da caixa de amortização, que era um organismo que estabelecia a credibilidade da política econômica instantaneamente.

Do ponto de vista teórico, para que uma estratégia de renegociação da dívida pública interna não implique inconsistência dinâmica, é necessária a criação de uma tecnologia de comprometimento. Do ponto de vista institucional e histó-

\footnotetext{
${ }_{47}$ "In turning over power to Poincaré, however, the moderate left placed important constraints on his freedom of action. First, the moderate left deputies were opposed to revaluation of the franc, and were in a position to block it if they could show that it caused hardship to any large group of voters. Second, the moderate left government bequeathed to Poincaré a staff of men in the top positions in the Bank of France who were sympathetic to their views." Schmid (1974: 376-375).

${ }^{48}$ Em alguns casos o Tesouro pode emitir dívida, mas apenas de longo prazo.

${ }^{49}$ Persson \& Tabellini (1994).
} 
rico, esta tecnologia é a legislação que cria e transfere para uma caixa de amortização o poder de gestão da nova dívida pública.

Zini $(1989,1992)$ e Z ini e Giambiagi (1993) buscaram aplicar alguns destes conceitos para 0 caso brasileiro $0^{50}$, em um período em que este tipo de abordagem parecia necessário. $\mathrm{N}$ estes artigos, o foco é que a existência de garantias ${ }^{51} \mathrm{e}$ de liquidez tornariam a dívida nova mel hor, de forma que os agentes aceitariam um provável desconto na conversão. Em paralelo à conversão da dívida, estaria um plano de estabilização da moeda ${ }^{52}$. A aplicação destes conceitos para o Brasil atual está fora do escopo deste trabalho e pode ser objeto de uma pesquisa posterior.

No entanto, dois trabal hos recentes, R einhart, Rogoff e Savastano (2003) e Reinhart e Rogoff (2004) chamam a atenção ao fato de que o nível de endividamento considerado seguro é inferior ao verificado atualmente, em países como 0 Brasil com uma longa história de defaults.

Como visto, em condições de sobreendividamento, a securitização é apenas mais uma estratégia que replica o comportamento de uma simples recompra ou perdão parcial.

As renegociações de sucesso ocorreram não apenas em função do instrumento de dívida que foi usado, mas do arranjo institucional e político que antecedeu a cada uma das renegociações ${ }^{53}$ e do processo de mudança institucional que ocorreu durante o processo de troca de dívida, e que garantiu a ausência de oportunismo depois da renegociação. 0 mecanismo mais usado é uma lei transferindo poderes para uma burocracia que passa a ser responsável pela gestão de algumas funções do Tesouro.

\section{REFER ÊN CIAS BIBLIOGRÁFICAS}

ALESIN A, A. (1988). "The End of Large Public Debts", In: Francesco Giavazzi e Luigi Spaventa, eds., H igh Public D ebt: The I talian Experience. Cambridge: Cambridge University Press: 3479.

; A. PRATI, A.\& TABELLINI, G. (1990). "Public Confidence and D ebt M anagement: a model and a case study of Italy". In: Rudiger Dornbush \& M ario Dragui Eds., Public D ebt $M$ anagement: Theory and History, CEPR e Cambridge University Press: 94-117.

ALM EIDA, R .O .M (1997). A R eestruturação e a Administração da Dívida Pública e suas Implicações M acroeconômicas - Tese de mestrado - Universidade de São Paulo -1997.

\footnotetext{
${ }^{50}$ Uma das alternativas de consolidação de Z ini e Giambiagi (1993: 12) “inspira(va)-se na experiência secular da fundação das dívidas públicas e em sua faceta contemporânea, que é a securitização das dívidas externas dos países em desenvolvimento."

${ }^{51}$ Estas garantias estariam "fora do alcance legal do executivo, para proteger seus recursos e obrigações) Zini (1992: 65).

${ }^{52}$ Giambiagi e Zini (1993: 6) e Zini (1992: 178).

${ }^{53} Z$ ini J r (1992: 65) reconhece a necessidade de um acordo político. "Para colocar a conversão em marcha é necessária uma negociação política para dar credibilidade e coesão à mudança de política" .
} 
BARRO, R. (1987). M acroeconomics, N ew York: Wiley 1987.

BLAN CHARD, O; DORN BUSH, R \& BUITER (1986). "Public Debt and Fiscal Responsibility" In: Olivier Blanchard, Rudiger Dornbush e Richard Layard (eds), R estoring Europe's Prosperity. Cambridge, M A: M IT Press: 125-133.

BORENSZTEIN, E. (1990) "Debt O verhang, Debt Reduction and Investment: The Case of Philippines", I M F Working Paper, W P/90/77.

BRESSER-PEREIRA, L.C. \& N AKAN O, Y.(2002). “Uma estratégia de desenvolvimento com estabilidade". M imeo.

CALOM IRIS, C (1988). "Institutional Failure, M onetary Scarcity, and the Depreciation of the Continental" The Journal of Economic History vol. X LVIII: 47-68

CALVO, G.A. \& GUIDOTI, P. (1990). "Indexation and M aturity of Government Bonds: an Exploratory M odel". In: Rudiger Dornbush \& M ario Dragui (ed). Public D ebt M anagement: Theory and H istory, CEPR e Cambridge University Press, Cambridge: 52-93.

CLAESSEN S,S. \& DIWAN , I. (1990)." Investment Incentives: N ew M oney, Debt R elief and the Critical Role of Conditionality in the Debt Crises". The World Bank Economic Review, 4: 21-41.

CLIN E, W.R. (1991). "M exico Economic Reform and Development Strategy" EXIM R eview, Special Issue. Tokyo: Export-Import Bank of Japan.

(1995). International Debt Reexamined. Institute for International Economics Washington DC - fevereiro 1995.

CORDEN , W. M . (1989). "Debt Relief and Adjustment Incentives" In: Frenkel, Dooley \& Wickman (eds). A nalytical Issues in D ebt. Washington: International M onetary Fund 1989.

DIAM ON D, D. \& DYBVIG, P. (1983). "Bank Runs, Deposit Insurance and Liquidity", Journal of Political Economy 91: 401-419.

DIWAN, I. \& KLETZER, K. (1992). "Voluntary Choices in Concerted Deals: The M enu A pproach to Debt Reduction in Developing Countries". The World Bank Economic Review, Vol.6 N o. 1: 91-108.

.\& ACH ARYA, S. (1993). "D ebt Buybacks Signal Sovereign Countries' Creditworthiness: Theory and Test." International E conomic Review, Vol. 34: 795.

DOR N BUSH , R. (1991). "Credibility and Stabilization", Q uarterly J ournal of E conomics, agosto: $836-850$.

DULLES, E. (1929). The French Franc, 1914-1928. N ew York: M acmillan, 1929.

DUN BAR, C.F.(1889). "Some Precedents Followed by Alexander H amilton" Q uarterly J ournal of Economics Vol.III: 32-59.

EATO N, J.(1993) "Sovereign Debt: A Primer" The World Bank Economic Review Vol. 7 N 0.2: 137172 1995.

EICHENGREEN, B. (1982). "Did Speculation Destabilize the French Franc in the 1920's?". Explorations in Economic History 19: 71-100.

. (1990). "The Capital Levy in Theory and Practice", in Rudiger Dornbush e M ario Dragui, (eds)., Public D ebt M anagement: Theory and $\mathrm{H}$ istory. Cambridge: Cambridge University Press: 191-223.

. (1992). "M ore on Speculation on Destabilizing Speculation". Explorations in Economic History , 29: 93-98.

FRAN ÇA (1926). Rapport des Experts mimeo.

FREKEL, J. M ICH AEL, D \& \& WICKM AN , P. (1989). A nalytical I ssues in debt. Washington: International $M$ onetary Fund.

FRO OT, K.a(1989). "Buybacks, Exit Bonds, and the O ptimality of Debt and Liquidity Relief". International Economic Review. Vol.30 N o. 1: 49-69.

GARBER, P. M . (1991). "Alexander H amilton's M arket Based D ebt Reduction Plan" N ational Bureau of Economic Research Working Paper N o. 3597 (janeiro 1991).

GIAVIAZZI, F. \& PAGANO M . (1990). "Confidence Crises and Public Debt M anagement" In: 
Rudiger Dornbush e M ario Dragui.(eds). Public D ebt M anagement: Theory and History. Ed. Cambridge University Press, Cambridge, 1990.

GROSSM AN, H . \& VAN HUYCK, J. B. (1988). "Sovereign Debt as a Contingent Claim: Excusable Default , Repudiation and Reputation". American Economic Review 78: 1088-97.

(1993). "N ominal Sovereign Debt, Risk Shifting and Reputation". Journal of Economics and Business: 341-352.

KEY N ES, J.M .(1932). A Tract on M onetary Reform, 1923; in Vol. IV dos The Collected Writings of Jonh M aynard Keynes (London :M acmillan, 1971)

KRUGMAN , P. (1988). "Financing Vs Forgiving a Debt: Some A nalytical N otes". Journal of D evelopment E conomics, 29: 253-268.

(1989) “M arket-Based Debt Reduction Schemes" In: Frenkel, D ooley \& Wickman, 1989.

KYNDLAND, F. \& PRESCOTT, E. (1977). "Rules Rather than Discretion: The Inconsistency of O ptimal Plans". Journal of Political E conomy 85: 473-91.

M AKINEN , G. \& WOODWARD, G. (1990). "Funding Crises in the Aftermath of World War I". In: Rudiger Dornbush e M ario Draghi.(eds). Public Debt M anagement: Theory and $\mathrm{H}$ istory. Cambridge University Press.

M ISALE, A. \& BLAN CHARD O.J. (1991) “The Debt Burden and Debt M aturity" N BER Working Papers series N 0. 3944.

M YERS, S.C. (1977). "D eterminants of Corporate Borrowing" . Journal of Financial Economics 5: $147-75$

PEEL, G. (1937). The E conomic Policy of France. M acmillan and Co. Ltd. London 1937.

PERSSO N T. TABELLIN I, G. (1994). M onetary and Fiscal Policy. Volume 1: Credibility. M IT Press.

PRATI, A. (1991). "Poincaré's Stabilization: Stopping a Run on Government Debt", Journal of M onetary E conomics 27: 213-239

PRIOURET, R. (1966). La Caisse des D épots - Cent Cinquante ans d'histoire Financeière - Presses Universitaires de France.

REIN HART, C. ROGOFF, H \& SVASTAN O, M . (2003). "Debt Intolerance”. Brookings Papers on Economic Activity, 1:2003: 1-74 mimeo

REIN HART, C. \& ROGOFF K. (2004). "Serial Default and The "Paradox" of Rich to Poor Capital Flows- artigo apresentado no American Economic Association M eetings em San Diego ( 6 de janeiro de 2004) a ser publicado no American Economic Review maio de 2004.

RO GERS, J.H. (1929). The Process of Inflation in France : 1914-1927. Columbia University Press $-1929$.

SACH S, J. (1989a). "The Debt O verhang of Developing Countries" In R onald Findlay et al., (eds.), D ebt, Stabilization and D evelopment - Essays in M emory of Carlos Diaz-A lejandro. Oxford: Blackwell: 80-102.

. (1989b) "Conditionality, Debt Relief, and the Developing Country Debt Crises". In: D eveloping Country D ebt and E conomic Performance, Vol.1. Ed. por J effrey D. Sachs. The University of Chicago Press: 255-295.

SAR GEN T, T. (1984) "Stopping M oderate Inflations: The M ethods of Poincaré and Thatcher" mimeo.

SCH M ID, G.C. (1974). "The Politics of Currency Stabilization: the French Franc, 1926" . Journal of European Economic H istory vol.3 n.02: 359-377.

SICSIC, P. (1992) "Was the Franc Poincaré D eliberately Undervalued? " Explorations in E conomic History 29: 60-92.

SM ITH , B.D. (1985). "A merican colonial monetary regimes: the failure of the quantity theory and some evidence in favor of an alternate view" Canadian Journal of Economics: 531-565.

SPAVEN TA, L. (1987). "The Growth of Public D ebt: Sustainability, Fiscal Rules and M onetary Rules". IM F Staff Papers XXXIV: 375-399.

STUDEN SKI, P. \& KRO OSS, H . (1952). Financial H istory of the U nited States. M acGraw-H ill Book Company York PA, 1952.

SWAN SO N , D. \& TROUT, A.(1990). "A lexander H amilton's Report on the Public Credit (1790) in a European Perspective". J ournal of European Economic H istory, Vol. 19 n. 3: 623-633.

SCHWARTZ, E. \& ZURITA, S. (1992). "Sovereign Debt: O ptimal Contract. Underinvestment and Forgiveness". The Journal of Finance. Vol. X LVII.N 0.3: 981-1004. 
SY LLA, R.; Legler, J. \& Wallis, J.(1987). "Banks and State Public Finance in the N ew Republic: The United States, 1790-1860." The Journal of Economic H istory Vol. X LVII: 391-404.

WEIR, D. (1989). "Tontines, Public Finance, and Revolution in France and England, 1688-1789." The Journal of Economic H istory, Vol. X LIX, N o. 1: 95-124.

ZINI JR ., A . A . (1989) "Fundar a Dívida Pública", Planejamento e Políticas Públicas 2: 39-60. . e GIAM BIA GI, F. (1993) “R enegociação da Dívida Interna M obiliaria: Uma Proposta, Revista de Economia Política Vol.13 N 0.2(50) (abril-junho 1993).

. (1992). Três Estudos sobre I nflação, Taxa de Câmbio e R eforma M onetária no Brasil Tese de Livre Docência. 